\title{
The Use of Supply Chains and Supply Chain Management in the Production of Forensic Maps Using Data from a Fraud Case
}

\author{
Peter Schmitz ${ }^{1,2,3}$
}

${ }^{1}$ CSIR Built Environment, Meiring Naude Rd, Brummeria, Pretoria, South Africa, pschmitz@csir.co.za

${ }^{2}$ Centre for Geoinformation Science, Department of Geography, Geoinformatics and Meteorology, University of Pretoria, Lynnwood Rd, Hatfield, Pretoria, South Africa.

${ }^{3}$ Fakultät für Vermessung, Informatik und Mathematik, Hochschule für Technik, Stuttgart, Schellingstrasse 24, D-70174, Stuttgart, Germany

http://dx.doi.org/10.4314/sajg.v5i2.5

\begin{abstract}
This paper is a case study that describes the production of $3 D$ visualisations for forensic maps that were used in a fraud case. The production path is followed from identifying the sources of data, the acquisition of the data (Source); the creation of the various $3 D$ visualisations (Make); and to the final report (Deliver). The various production processes are the acquisition of the data, the selection of software, data clean-up and preparation, the $3 D$ mapping, and the writing of the report based on the analysis. The production path is based on supply chains and supply chain management using the Supply-Chain Operations Reference (SCOR) model as a guideline. Three distinct periods of interest to the investigation were identified and mapped. The aim of the paper is to illustrate the use of supply chains and supply chain management to guide the production of maps. Supply chain management can be used for any type of project whether small or very large and complex.
\end{abstract}

\section{Introduction}

During the end of December 2011 and the first few days in January 2012, 42 million Rands were fraudulently transferred into various accounts using a bank's ${ }^{1}$ mainframe computers in Bloemfontein. Access to the mainframe was through a specialised modem provided by a criminal syndicate using an active network point that was not de-activated when the redundant computers were removed from the bank's unused offices and service points. Several hundred fraudulent accounts were created on the $28^{\text {th }}$ of December. The money was transferred into the accounts on the night of 31 December 2011 and the early morning of 1 January 2012. Each account had a R500 000 withdrawal limit. The syndicate used runners with fraudulent bank cards to withdraw the R42 000000 over a three day period. The Hawks managed to apprehend the criminals involved and needed to show how the kingpin and his henchmen were involved in the planning and execution of the crime. The 
investigators identified three main events, namely the initiation of the syndicate and fraud on the $4^{\text {th }}$ December $2011 ; 25$ to 28 December 2011 was the setting it up using the modem and the mainframe in Bloemfontein; and 30 December 2011 till 3 January 2012 the execution of the fraud. The execution of the fraud included the transfer of R42 000000 into the various accounts and the withdrawals from the ATMs in Kwa-Zulu Natal, the Free State and Gauteng (Pieterse, personal communication, February 2013).

The investigators requested the CSIR to map the movements and communications of the identified individuals using cellular telephone data. Cellular telephone data plays an important role in investigations since it leaves a trace that allows investigators to determine whether the criminal was at a location where a crime has occurred (Lochner \& Zinn, 2014). Members of the criminal syndicate would drive long distances to have short face-to-face meetings and return to their respective locations. To demonstrate these movements and meetings it was decided to use 3D mapping. The latitude and longitude was used to map the spatial location, and time was used to map location on a vertical axis. The final deliverable was a report showing the various $3 \mathrm{D}$ maps as they relate to the three identified periods. The CSIR has been involved in forensic geoscience since 1998 and was instrumental in conviction several suspects in cases such as the Marlize Holmes kidnap, rape and murder case (Schmitz et al., 2000); the Taliep Petersen murder case (Schmitz et al., 2009) and the Judge Maqubela case (Schmitz et al., 2013).

Supply chains and supply chain management was used in the production of maps and reports in some of the criminal cases. Mapping the supply chain gives structure to the project, leaves a clearly defined audit trail, can be used in determining workflows and distributed workflows, and lends the ability to find opportunities to reduce errors and improve the quality of the spatial products delivered. Workflows are part of the MAKE process (Schmitz, 2007).

The rest of the paper is as follows: The next section discusses supply chains and supply chain management including the SCOR model used during the production of the forensic maps and report. This is followed by a short discussion on 3D visualisation and its application in the forensic context and why it was chosen for this project. The process followed in producing the maps is then discussed using examples. The paper ends with conclusions and recommendations.

\section{Supply Chains and Supply Chain Management}

A basic supply chain consists of a supplier, a manufacturer and a customer at the other end (Christopher, 1998 and Mentzer et al., 2001). A supply chain is defined as follows: The supply chain encompasses all activities associated with the flow and transformation of goods 
from the raw materials stage (extraction), through to the end user, as well as the associated information flows. Material and information flow both up and down the supply chain (Handfield \& Nichols 1999:2). In the context of GIS, the supplier provides the spatial and non-spatial data, the manufacturer is the GIS unit or company and the customer is the person or entity that receives the spatial data or map (Schmitz, 2009). A hypothetical GIS supply chain is shown in Figure 1.

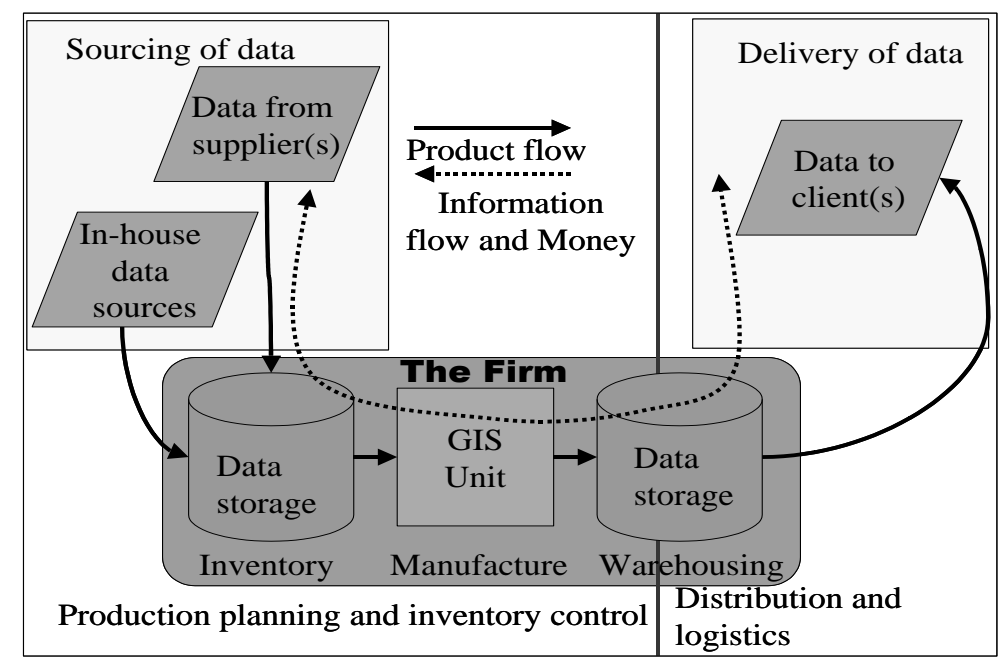

Figure 1. A hypothetical GIS supply chain (Figure 1.6, Schmitz 2007:21)

The supplier is the source of data for the GIS unit/company. The GIS unit/company can be its own supplier of data. In-house data sources are sources of data from other units in a company or institution in which a GIS unit is situated. The inventory is all the various data layers a GIS unit/company may have. Manufacturing in the context of GIS is the creation of value-added spatial data by the GIS unit to create the final product using GIS software, spatial data, hardware, and GIS personnel. Inventory is part of data warehousing and the final product is also stored in a data warehouse before delivery to client/customer. The request for a specific product initiates the supply chain (Schmitz, 2007).

Supply chain management is used to manage the supply chain and is defined as follows: The management of upstream and downstream relationships with suppliers and customers to deliver superior customer value at less cost to the supply chain as a whole (Christopher, 1998:18).

Supply chains can be sophisticated and complex, such as those of the automotive and pharmaceutical industries, or can simply involve a few suppliers and a customer. The SupplyChain Operations Reference (SCOR) model has been developed to assist industries to map, analyse and improve their supply chains (Bolstorff \& Rosenbaum, 2007). The SCOR model was developed by the Supply-Chain Council, which merged with APICS in 2014 (www.apics.org). The Supply-Chain Council was a not-for-profit organisation serving the 
supply chain management environment, and APICS is one of the leading professional associations for supply chain managers since 1957 (www.apics.org). The SCOR model framework consists of PLAN, SOURCE, MAKE, DELIVER and RETURN management processes. PLAN assesses the supply chain with regards to resources, demand requirements, planning the sourcing, production and delivery and the capacity to fulfil the demand on the supply chain. It also aligns the supply chains to the financial strategies of the company. SOURCE looks at the selections of suppliers, the acquisition of products and the verification thereof, storage of the sourced products and the payment of suppliers. MAKE is the production part of the supply chain. It schedules the productions, releases the sourced products needed for manufacturing, quality control and the storage of work-in-progress and completed products before delivery. DELIVER deals with the delivery to and installation of completed products at the customer's site. The RETURN part of the supply chain handles the return of defective products, products that needs to be overhauled, maintained or repaired, and excess products that needs to disposed of responsibly or those that will be recycled (Bolstorff \& Rosenbaum, 2007). Each management process has enabling functions such as supplier data, inventory management, business rules, regulations, and capital equipment management.

Each of these management processes has various process categories. These process categories for SOURCE (S), MAKE (M) and DELIVER (D) are guided by the production process followed, namely stocked items (S1, M1 and D1), Make-to-Order products (S2, M2 and D2), and Engineer-to-Order products (S3, M3 and D3). Stocked items are products that you can buy of the shelf such as mineral water, clothes and toiletries, or in the spatial data context digital 1:50 000 topographic maps. Make-to-Order products are products that will be manufactured according to an established production process once an order has been received. Examples are high-end motor vehicles or georectified satellite images. Engineer-toOrder products are unique, once-off and are designed from scratch. Most of the GIS consulting work will fall into this category. The process categories for PLAN are P1 plan the supply chain, P2 plan SOURCE, P3 plan MAKE, P4 plan DELIVER and P5 plan RETURN. RETURN process categories fall into two classes namely SOURCE RETURN, where defective products (SR1), products that need to be maintained, repaired or overhauled (MRO) (SR2) or excess products returned (SR3), and DELIVER RETURN. DR1 deals with defective products, DR2 with MRO products and DR3 with excess products (SCC, 2008).

These processes categories are further decomposed into process elements which describe the processes involved to execute the supply chain. An example is S1: Source Stocked Item which is decomposed into S1.1 Schedule Product Deliveries; S1.2 Receive Product; S1.3 Verify Product; S1.4 Transfer Product; and S1.5 Authorise Supplier Payment. Each of these process elements are then decomposed further into implementation processes. The SCOR 
model only covers the processes up to process element level since the implementation processes are company specific (SCC, 2008). Figure 2 gives an example of process elements involved in sourcing survey data from SAS Protea, a hydrographic survey vessel of the South African Navy (S2: Source Make-to-Order Product). Process elements give the various steps according to the SCOR model that can be followed when planning, sourcing, producing, delivering, and returning products and raw materials (SCC, 2008). Figure 3 shows the implementation processes for S2.3: Verify Product.

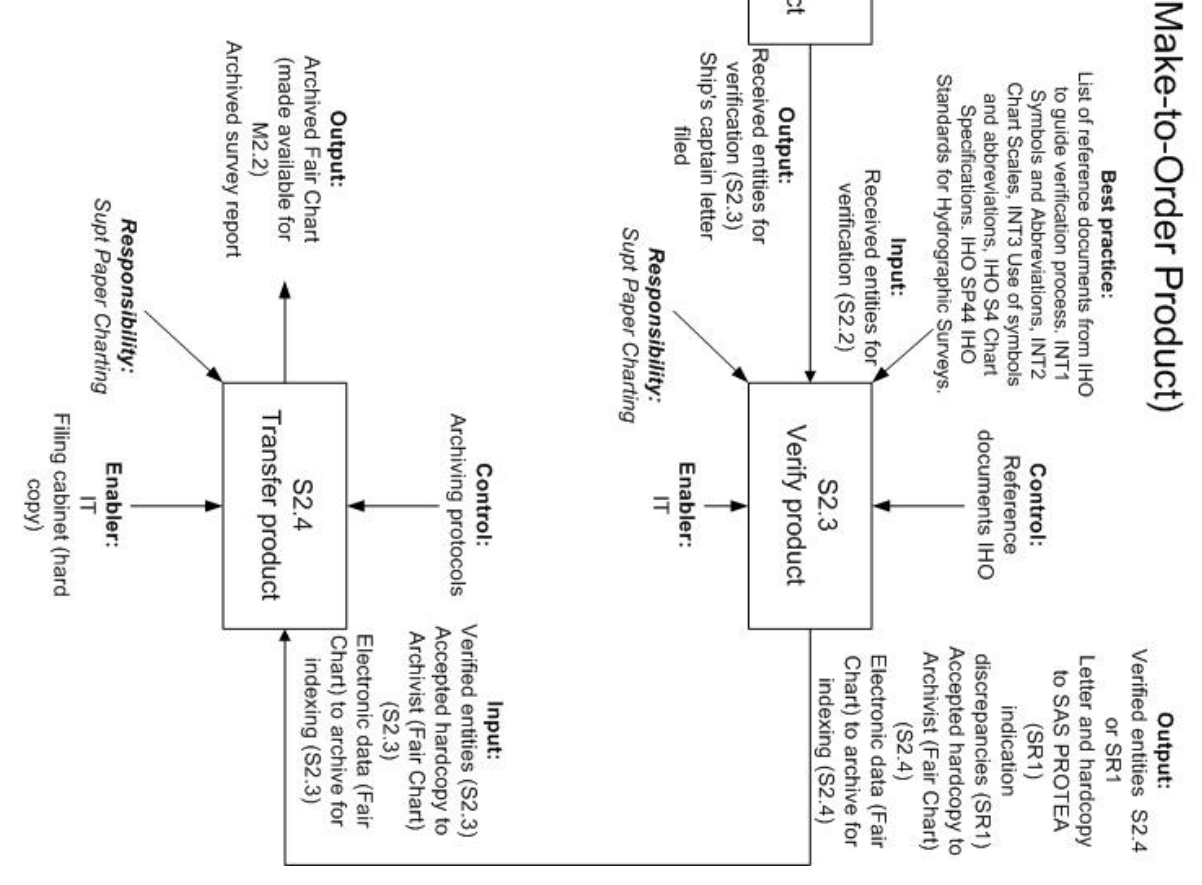

Figure 2. S2 process elements (Schmitz et al., 2011) 


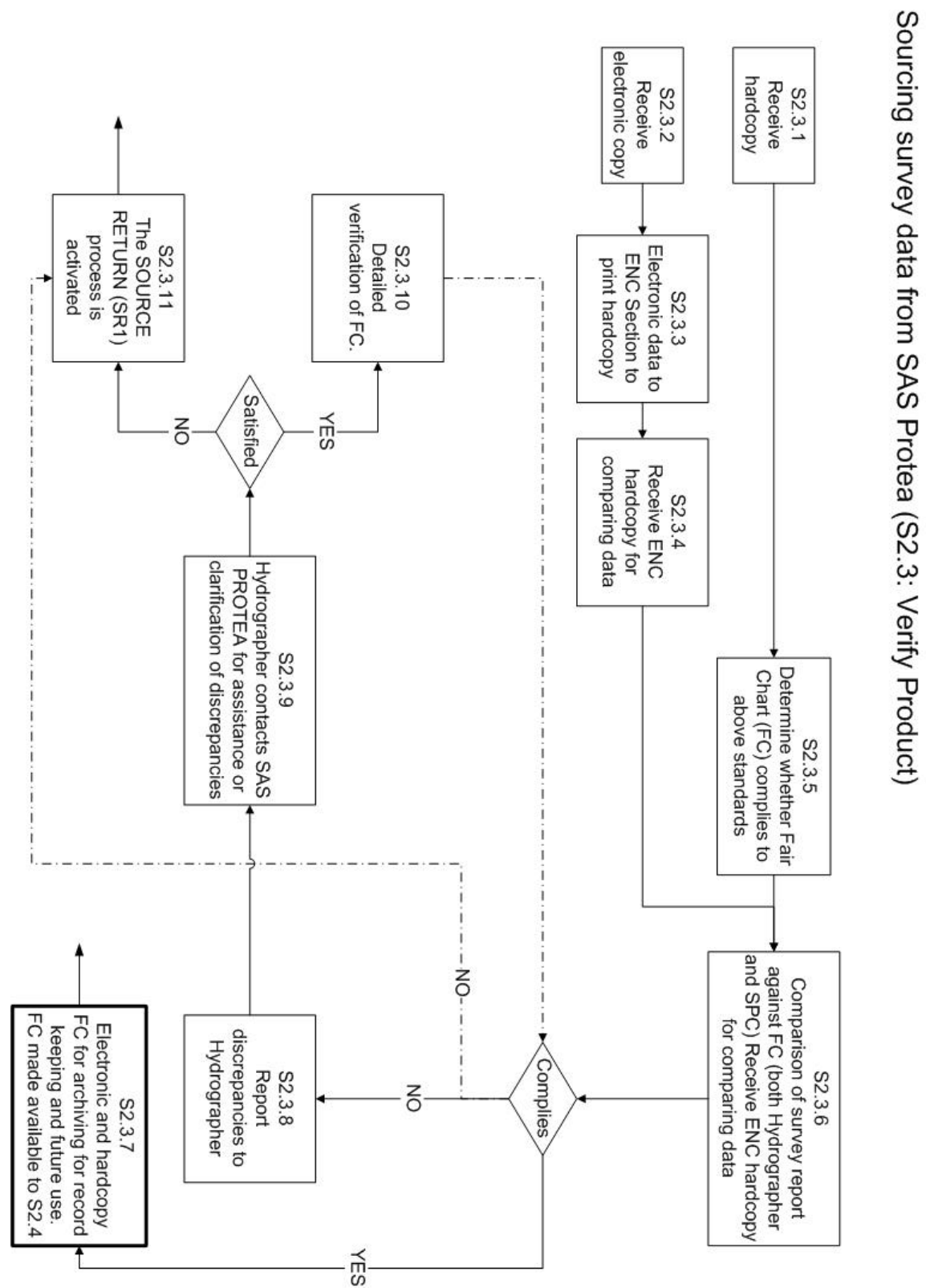

Figure 3. S2.3 implementation processes (Schmitz et al., 2011)

A definition of various metrics and best practices are linked to each of these processes at the various levels as illustrated in Figure 4. Although the SCOR model is designed for sophisticated and complex supply chains, it can be used for small and simple supply chains as well. The model is designed in such a way that only those processes, categories, elements and metrics that are relevant to the supply chain are selected (Bolstorff \& Rosenbaum, 2007). Based on this, the SCOR model can be used as a guide to plan and execute a small project as illustrated in this paper. Other applications of the SCOR model in Geoinformation are mostly based on the author's PhD work (Schmitz, et al, 2005a; Schmitz, et al, 2005b; Schmitz, 2007; Schmitz, et al, 2007; Schmitz, 2008; Schmitz 2009 and Schmitz, 2011) and analysing the SDI supply chains by Kurwakumire, et al, 2013 and Kurwakumire, et al, 2014). Before the application of the SCOR model will be discussed, 3D visualisation and its use in forensic geoscience needs to be discussed. 
Source Stocked Product

The process of ordering, receiving and transferring raw material items, sub-assemblies,

product and or services based on aggregated demand requirements. The intention of

Source-to-Stock is to maintain a pre-determined level of inventory for these materials, sub assemblies or products. No customer reference or customer order detail is exchanged with the supplier, attached to or marked on the product, or recorded in the warehousing or ERP system for Source-to-Stock products. Examples of alternative or related names for Sourceto-Stock are: replenishment inventory, drip parts, kan-ban, andon, and bulk or generic stock.

\begin{tabular}{ll}
\hline Performance Attributes & Metric \\
\hline Supply Chain Reliability & None Identified \\
\hline Supply Chain Responsiveness & $\begin{array}{l}\text { Source Cycle Time, } \\
\text { Order Fulfillment Cycle Time }\end{array}$ \\
\hline Supply Chain Agility & None Identified \\
\hline Supply Chain Costs & Cost to Source, \\
& Product Acquisition Costs \\
\hline Supply Chain Asset Management & Return on Supply Chain Fixed Assets, \\
& $\begin{array}{l}\text { Return on Working Capital, } \\
\text { Inventory Days of Supply (Raw Material) }\end{array}$ \\
\hline Best Practices & Description/Definition \\
\hline Select suppliers with EMS & Select suppliers with active EMS systems \\
\hline Joint Service Agreements (JSA) & Collaborative Planning Systems \\
\hline Utilize green purchasing practices & Utilize green purchasing practices \\
\hline
\end{tabular}

Figure 4. Process definition, metrics and best practices (SCC, 2008:3.2.2)

Linked to the various process elements as discussed above, there are various metrics that can be used to measure the performance of the supply chain. The SCOR model has five classes of measures, namely reliability, responsiveness, agility, costs and asset management. Reliability looks at how reliable the supply chain is in terms of order fulfilment, schedule achievement, percentage of transaction errors, etc. Responsiveness deals with the various time spent on creating the product, receiving it, packaging the product and sending the product to the customer to list a few metrics. Supply chain agility looks at how quickly the supply chain can react to outside influence before incurring penalties such as loss in production or penalties paid for late delivery. Cost are all the cost involved in producing the product, ranging from administration costs, cost of assets, costs of sourced products to direct labour costs. Asset management deals with the return of the various assets and working capital (SCC, 2008).

\section{3D Visualisation and Application in Forensic Geoscience}

3D visualisation has a wide range of applications from the medical field, 3D surveillance (Fleck et al., 2006) to 3D geovisualisation (Kraak, 2003). Figure 5 shows a 3D visualisation of the lung, heart, aorta, arteries and veins derived from CT scans used for training medical students (Silen et al., 2009). 


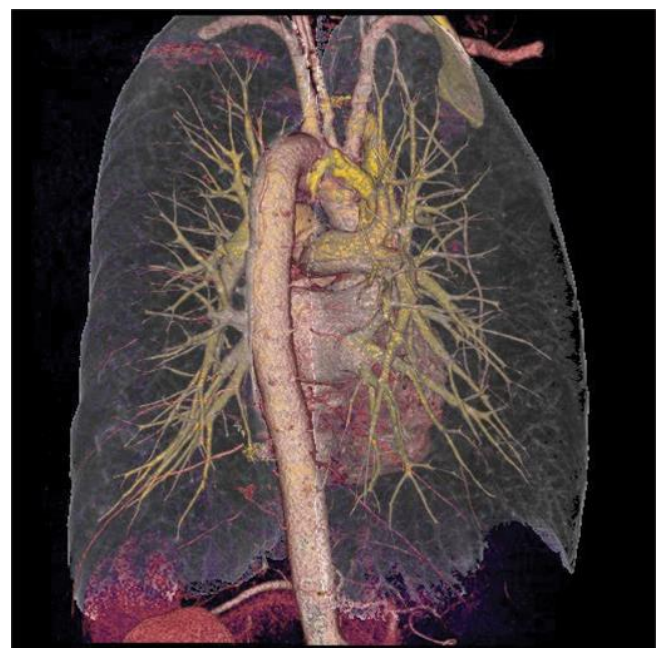

Figure 5. 3D image of the heart, lungs, aorta, arteries and veins (Silen et al., 2009:e119)

In the GIS environment 3D maps and images are used in town planning (Altmaier \& Kolbe, 2003 and Xu \& Coors, 2012); facility management (Altmaier \& Kolbe, 2003); geology (de la Losa \& Cervelle, 1999 and $\mathrm{Wu} \& \mathrm{Xu}, 2003$ ) as illustrated in Figure 6, and mapping the movement and communication of criminals over time and space (Schmitz et al., 2015). There are several formats to display time and space in GIS of which Hägerstrand's space-time cube is the most applicable for mapping criminals' movements and communications (Schmitz et al., 2015). In Hägerstrand's space-time cube, the location (X,Y) is given by two horizontal axes and the vertical axis $(Z)$ gives the time (Kraak, 2003 and Kristenson et al., 2008).

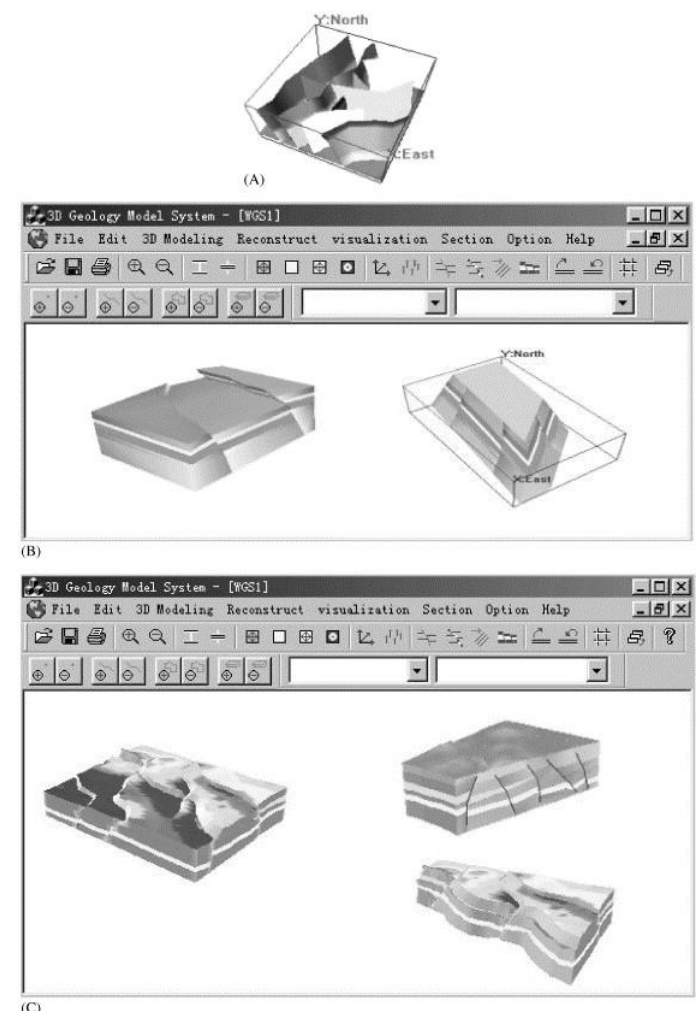

Figure 6. 3D geology modelling (Wu \& Xu 2003) 
Time can be displayed either ascending, meaning the older time is located at the X,Y plane and the more recent time at the top of the cube as shown in Figure 7, illustrating Napoleon's 1812 Russian campaign, or the other way around with older time at the top of the cube as illustrated in Figure 8.

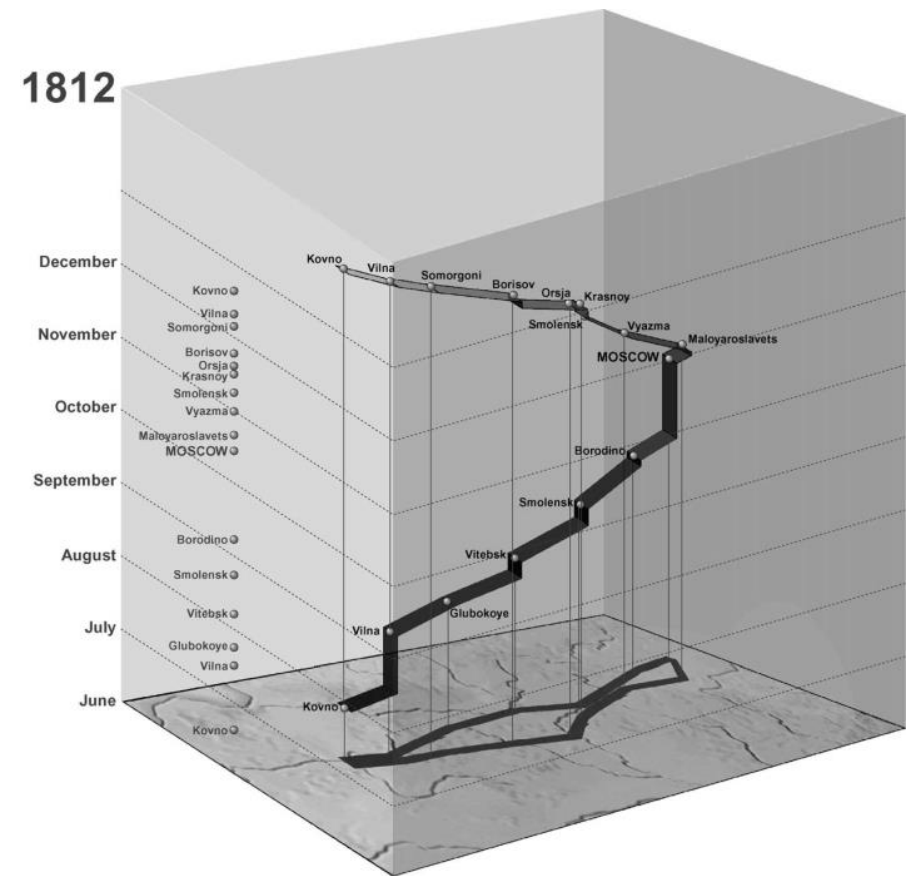

Figure 7. Space-time cube with the more recent time at the top (Kraak, 2003)

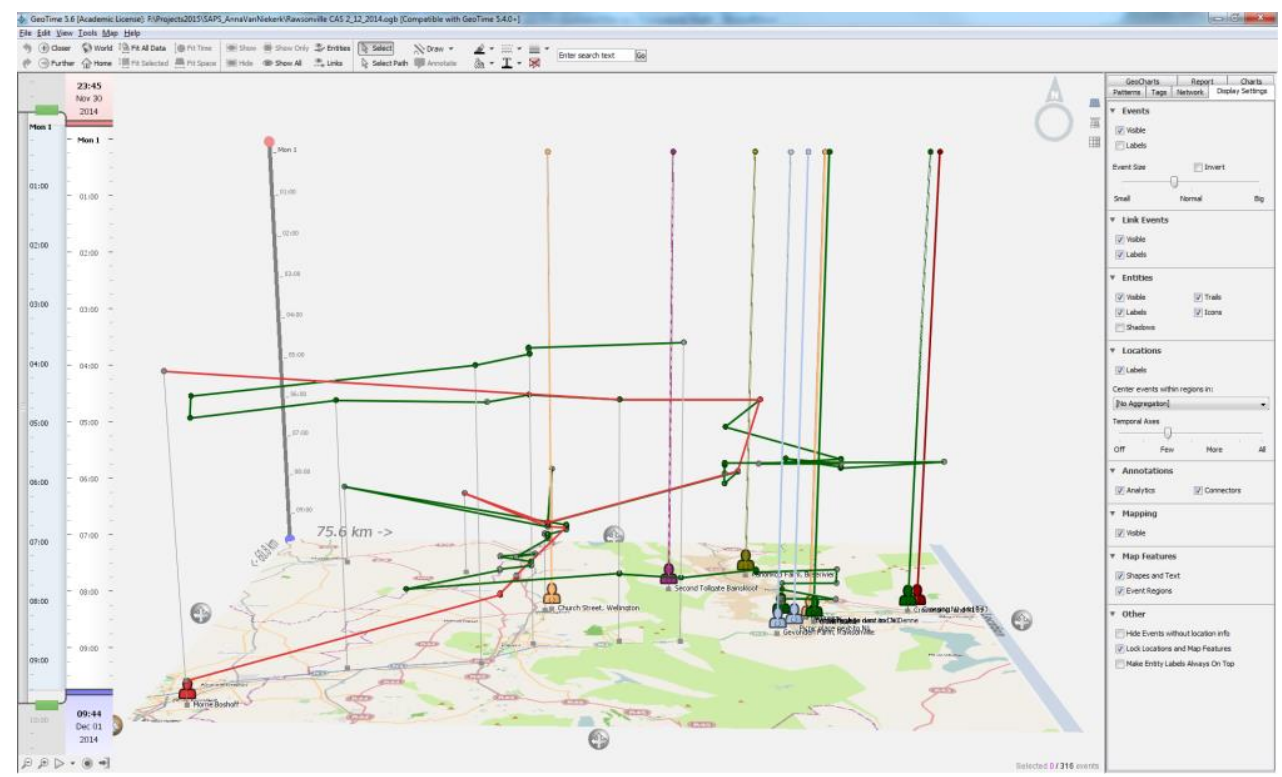

Figure 8. Space-time cube with the more recent times at the XY plane

Figure 8 was generated using GeoTime 5.6 from Uncharted Software Inc. The remainder of the paper will look at the production of the space-time cube for the bank fraud case using GeoTime 5.6. 


\section{The Production Process to Create 3D Visualisation of the Bank Fraud Case}

As indicated in Section 1, the investigation into the bank fraud required maps to show the movements and communication between crime syndicate members on three separate occasions. Although this was a small project the aim of this paper is to illustrate the use of supply chains and supply chain management. Planning of this project's supply chain will be discussed in the next sub-section. The request from the Hawks to create the maps and 3D visualisation initiated the supply chain. This was followed by a quote which was accepted by the Hawks. The latter two activities will be shown in the DELIVER part of the SCOR model.

\subsection{PLAN}

Although PLAN in the SCOR model is very detailed for large supply chains, it suffices for small projects to have an all-encompassing plan for covering the aspects of a supply chain. This project fell within the financial plan of the GIS unit or the company at large. With regards to resources, the required software and hardware were in place, thus it was not necessary to buy new software and hardware. The product that the customer required was a written report showing maps and 3D space-time cubes. The necessary office software was available. IT support and office space were available. The production was an engineer-toorder product (M3). Thus the only detailed planning requirement was the sourcing of the data that was used in the project. The data required were:

- Cellular telephone data from service providers. This was acquired via the Hawks using a Section 204 court order served unto the service providers.

- Cellular base stations via a Section 204 court order.

- Base data such as roads and towns, which were available in the data warehouse.

- ATM locations and transactions from the various banking institutions.

\subsection{SOURCE}

SOURCE looks at the acquisition of the data required for the project. Figure 9 shows the processes involved. The Hawks provided the cellular telephone detailed billing records in an electronic format. They further included all the relevant telephone numbers that pertained to the investigation. The Hawks obtained these from the various service providers using a Section 204 court order. These were verified with the investigators to be the correct billing records and placed into a folder for further use. These were stocked items (S1) since the service providers have 36 months of data available according to law. Once a court order was received the service provider extracted the information for the specified period as indicated. 
The Hawks also provided the ATM transactions and locations that they received from the banks. These records were stocked items (S1). The banks extracted the transaction records and provided the locations of the ATMs used. These were verified and placed in the same folder for further use.

Using the billing records, the various cellular base stations, alternatively known as cell towers, were identified and acquired via a Section 204 court order. These were stocked items (S1) since they were used by the service providers for planning purposes. The service providers continuously upgrade their service network and have the locations of the base stations in a GIS format. The locations and names of the requested base stations were extracted and provided to the investigating officers.

Base data such as roads and towns were obtained from in-house sources and OpenStreetMap. OpenStreetMap was the base layer used for the 3D space-time cube mapping. The software required a real-time link to OpenStreetMap to obtain the data. These data layers were stocked items (S1). The next section discusses the MAKE processes.

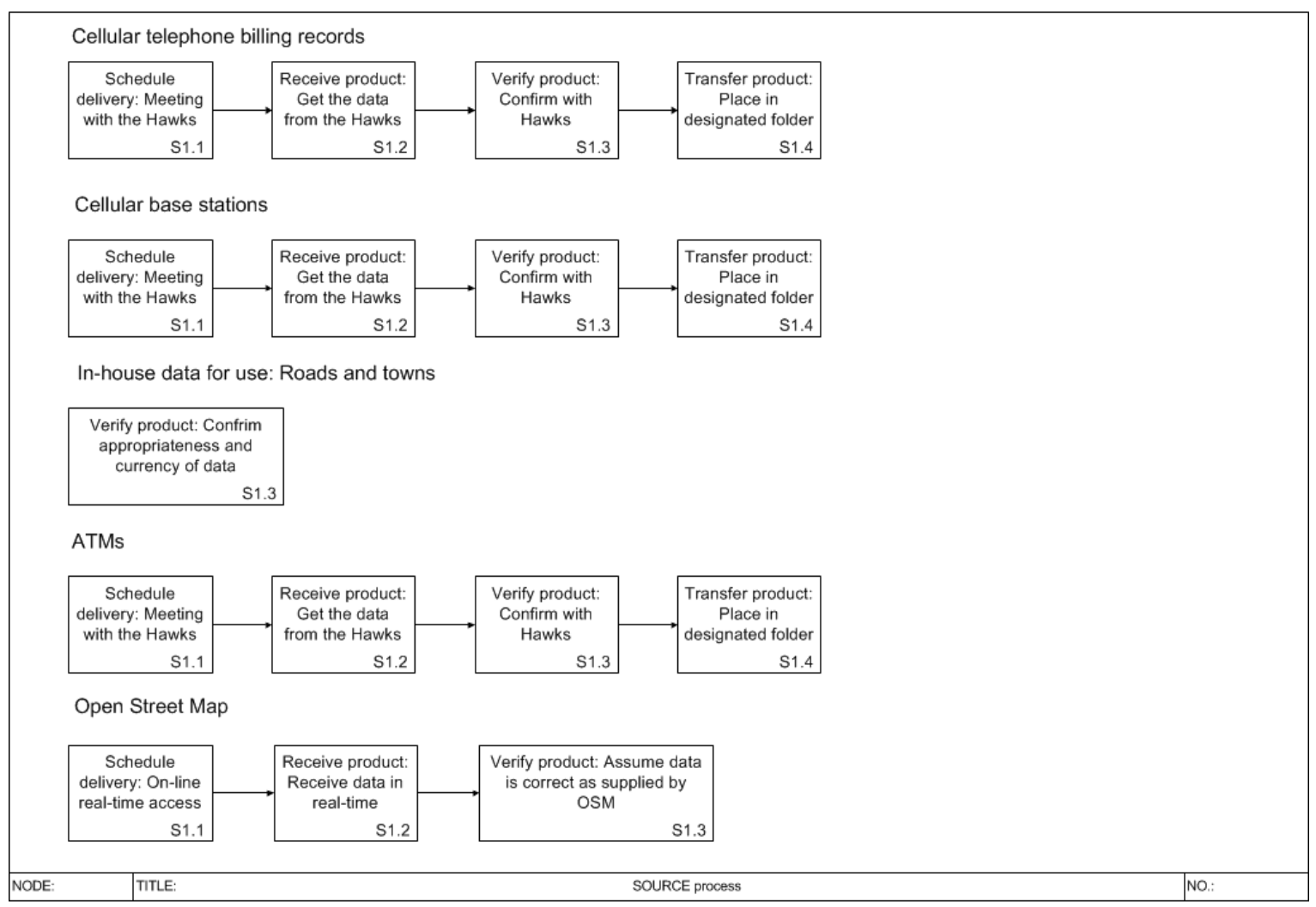

Figure 9. Source processes involved in acquiring the data

The source enabling process that was applicable to this project was Enable Source (ES4): Manage Product Inventory. This process guided the placing of the received data in the project folders and the availability of in-house data. This ensured that the data was backed-up and accessible by other designated persons in the absence of the project members. 


\subsection{MAKE}

MAKE is the production process. There were five MAKE processes involved which provided the products for the final product. The final product was a report. The two MAKE process categories involved in the production was Make-to-Order (M2) and Engineer-toOrder (M3). The first MAKE process involved the identification of the cellular base stations that was of interest to the investigation. These base stations were then forwarded to the investigators and they requested the locations from the service providers. These base stations were then used as an input to map the locations in $2 \mathrm{D}$ and $3 \mathrm{D}$. The second process involved the geocoding of the ATMs and the times of interest was captured as an attribute.

The third process was the creation of 3D space-time cubes using inputs from the billing records, base stations and ATM locations. The fourth process was the creation of $2 \mathrm{D}$ maps that formed part of the report. This process is mentioned but is outside the scope of this paper. The last process was the creation of the final report which included the maps and 3D space-time cubes. These processes are shown in Figure 10. Not all the process elements were mapped as can be seen in Figure 10 owing to the fact that if it was not required, it was not mapped. The SCOR model allows for the selection of applicable process elements without jeopardising the model. The following enable elements were applicable:

- EM.4: Manage In-Process Products which looked at the placement of work-inprogress products which were assembled into the final product. In this example, it was all the maps and 3D space-time cubes that were generated into the final report.

- EM.5: Manage Make Equipment and Facilities. This pertained to management of computers, software, office space and equipment.

- EM.8: Manage Make Regulatory Environment. In this project it appertained to GIS standards and the proof that the data about the suspects were obtained via a Section 204 court order.

Figures 11 to 13 shows examples of the 3D space-time maps created during the MAKE process for inclusion into the report. Figure 11 shows the ATMs and cellular base stations used by Suspect 1. Figure 12 shows the handover of the device that was used to get access to the bank's mainframe, and Figure 13 shows the creation of the fake accounts using the numbers that were forwarded to the person in Bloemfontein. The next section discusses the DELIVER process elements. 
Extracting cellular base stations from billing records

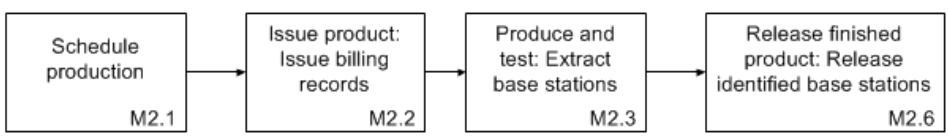

Geocode ATMs and times of activity

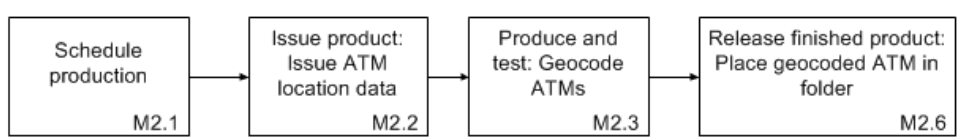

Create 3D space-time cubes

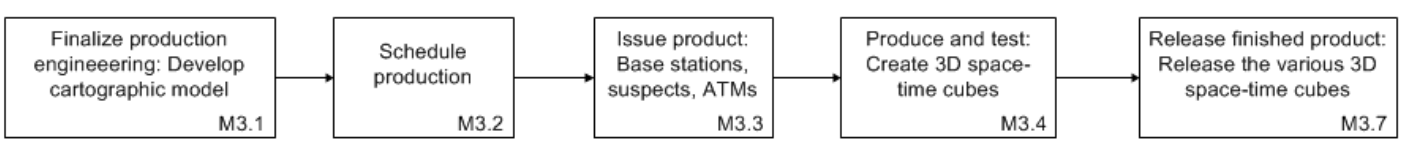

Create maps (not part of this paper)

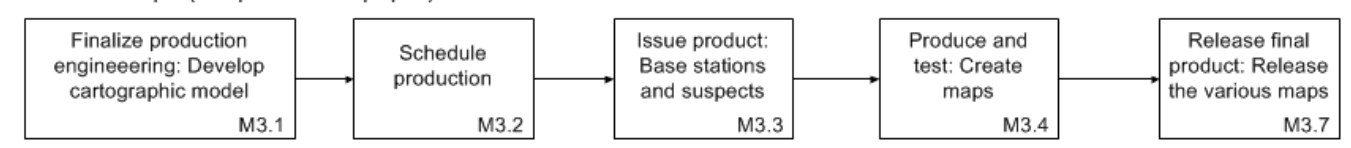

Report

\begin{tabular}{|c|c|c|c|c|}
\hline $\begin{array}{l}\text { Schedule } \\
\text { production }\end{array}$ & $\begin{array}{l}\text { Issue product: Maps } \\
\text { and 3D space-time } \\
\text { cubes }\end{array}$ & $\begin{array}{c}\text { Produce and } \\
\text { test: Write report }\end{array}$ & $\begin{array}{l}\text { Release finished } \\
\text { product: Release } \\
\text { report to the Hawks }\end{array}$ & \\
\hline M2.1 & M2.2 & M2.3 & M2.6 & \\
\hline TITLE: & & & cess & NO.: \\
\hline
\end{tabular}

Figure 10. The various MAKE processes involved

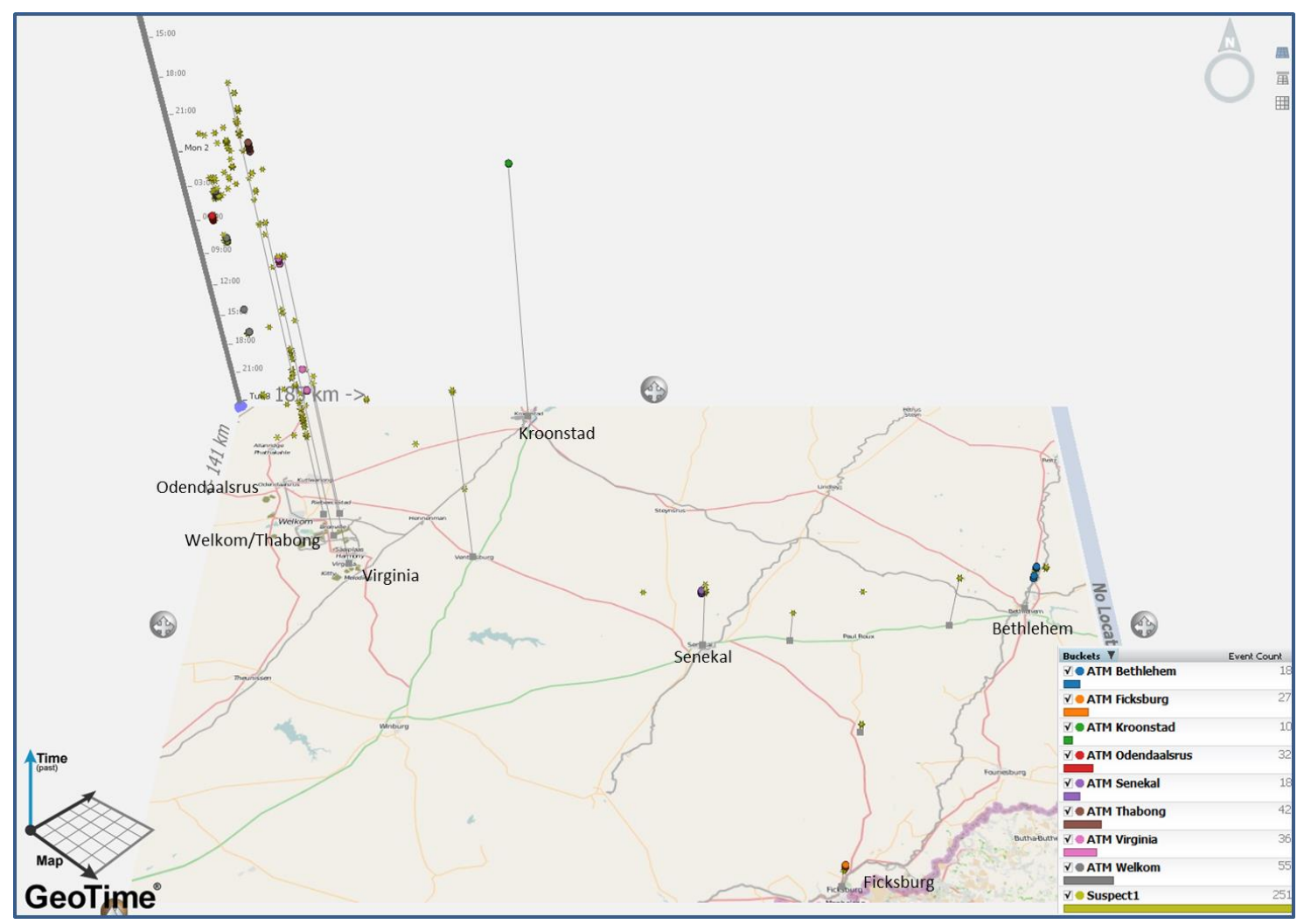

Figure 11. Base stations and ATM usage by Suspect 1 


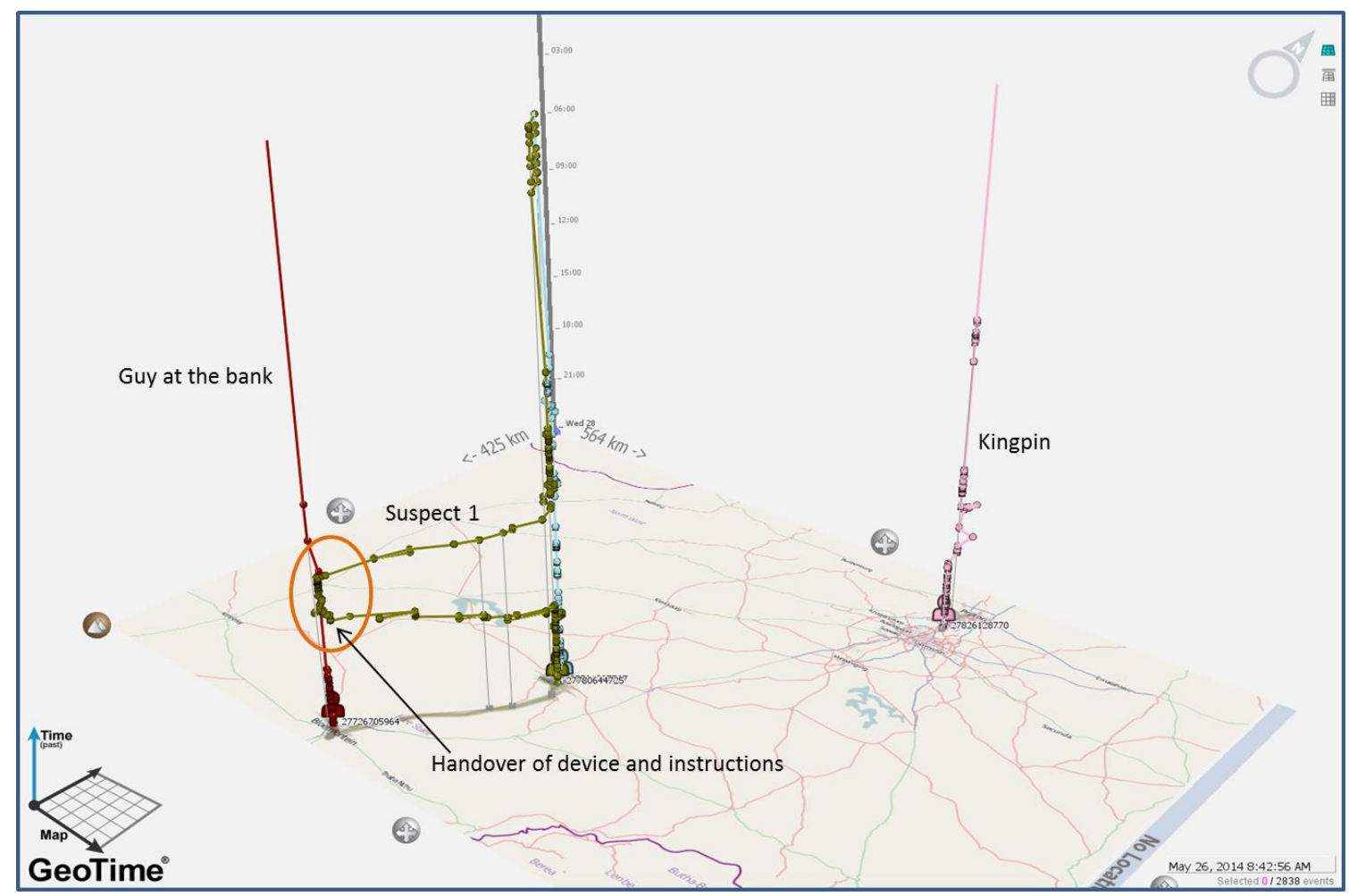

Figure 12. The handover

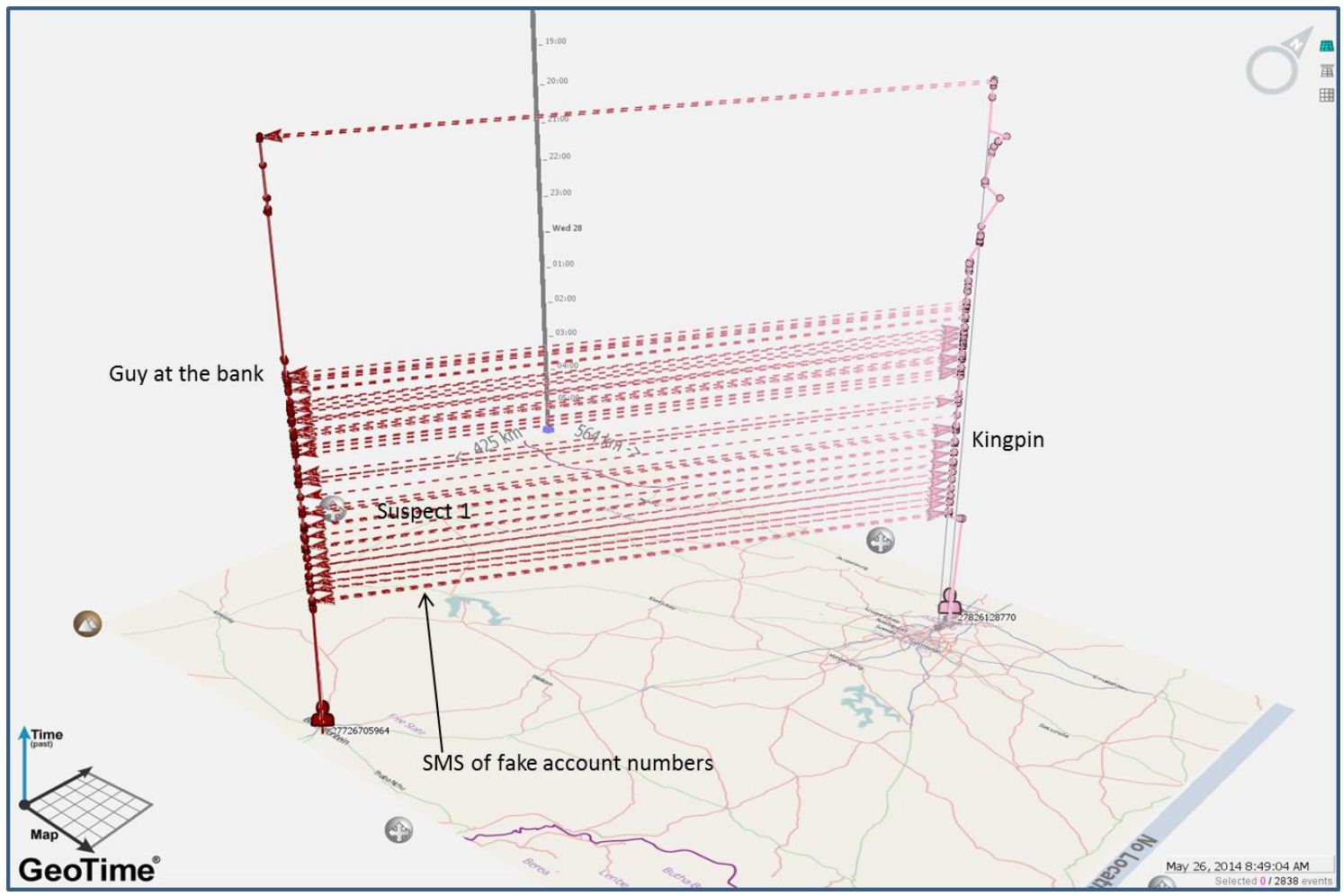

Figure 13. Setting up the fake accounts

\subsection{DELIVER}

The final product was a Make-to-Order product, thus the DELIVER process category was Deliver Make-to-Order Product (D2). 


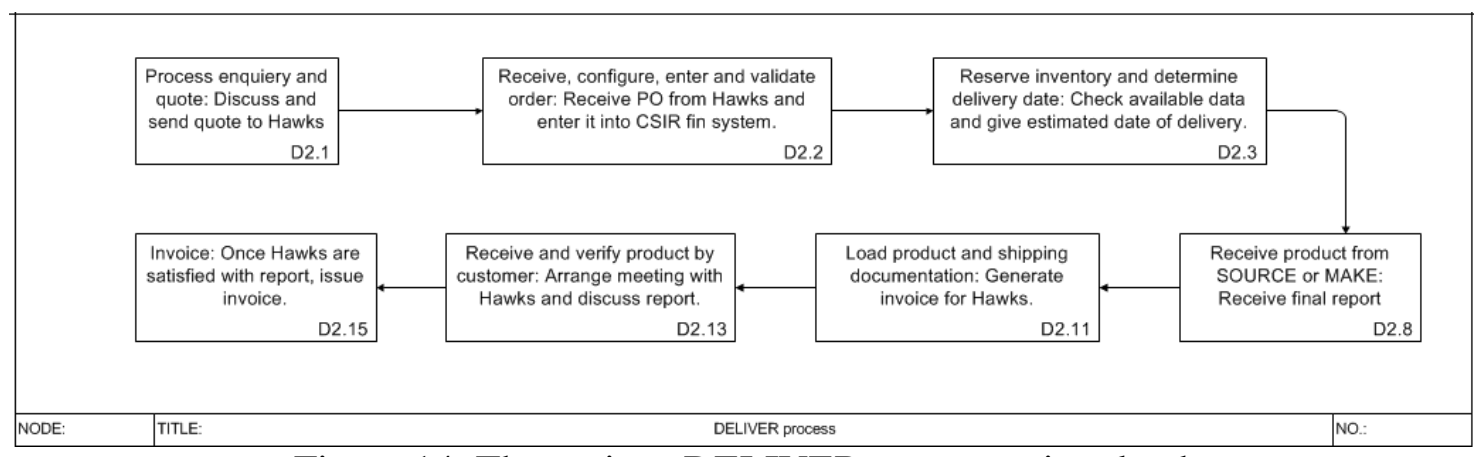

Figure 14. The various DELIVER processes involved

D2.1 and D2.2 were the processes that initiated the supply chain as indicated in Figure 14. The reason for being on the DELIVER side of the supply chain is that in the SCOR model DELIVER is customer facing. D2.2 activated the sourcing and production. With regards to D2.11, invoice generation was part of shipping documentation, hence the inclusion. Owing to the nature of the report, a meeting was held with the investigators from the Hawks. The report was discussed in detail and the necessary changes were made (D2.13). The Hawks signed off the final approved report (D2.13) and an invoice was issued (D2.15).

The following enabling processes were applicable to DELIVER with regards to this particular project:

- ED.1 Manage deliver business rules: These were the rules of the organisation with regards to doing contract work, project registration and generating invoices.

- ED.4 Manage finished goods inventory: The directories and folders for data, reports and maps.

The next section discusses the RETURN processes.

\subsection{RETURN}

The RETURN process only dealt with the customer in this project. In the SCOR model, it was Deliver Return Maintenance, Repair or Overhaul (MRO) Product (DR2). With regards to this project it was seen as updating the report based on new information and data provided during the discussion of the report in D2.13 (DR2.2 and DR2.3). The report was then updated based on their input. This was mainly due to new insights provided by the report itself or new information that became available during the ongoing investigation. The investigators were also involved in the MAKE process to clarify certain information with regards to the suspects. RETURN feeds back into either SOURCE or MAKE (DR2.4). The SOURCE process for new data that became available during ongoing investigations and MAKE if no new data was made available. In this line of work there may be several iterations before the 
final report is delivered. Figure 15 shows the various applicable RETURN processes. For this project there were no Enable Return processes since this was part of the DELIVER process.

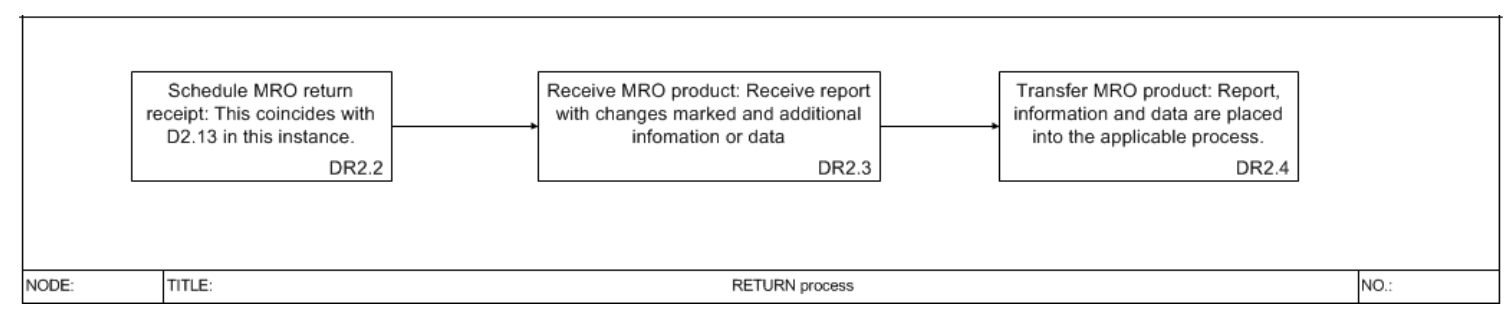

Figure 15. The RETURN processes

\subsection{The Supply Chain}

Figure 16 shows the complete supply chain for this project using the elements as discussed in the aforementioned sections. PLAN encompasses the whole supply chain. The identification of the cellular base stations were done first since these provided the spatial component to the billing records to create maps. The ATMs were geocoded in order to compare their transaction times with the billing records. OpenStreetMap was used as a backdrop to GeoTime's generation of the 3D space-time cubes.

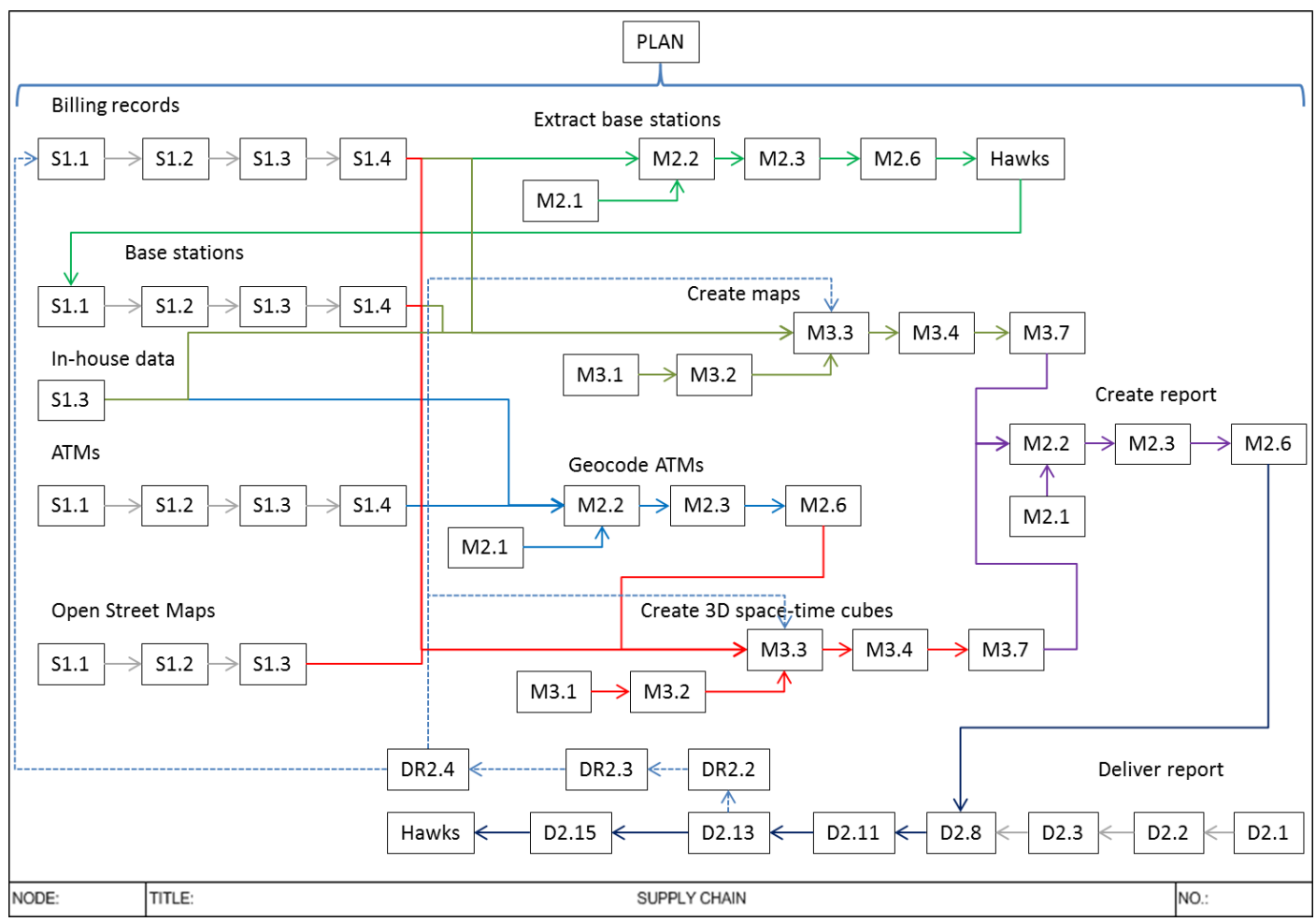

Figure 16: The supply chain to create the final report

\section{Conclusions}

Bolstorff \& Rosenbaum (2007:xiii) indicated once you define the supply chain, you can measure it and once you measured it you will find opportunities to improve it. The SCOR model was used in this example to illustrate how a supply chain can be defined even if it is 
for a small project. The same model can be applied to any size of GIS project or product range.

The supply chain provided a structure to the project, meaning it can be used as a project management tool. It provides a tool to improve future projects based on the lessons learned in this project, such as making provision for sourcing problems, meaning you have to make provision for lead times when ordering data. In this instance you have to accommodate the time it takes for the Hawks to obtain a Section 204 warrant to source the data from the service providers and the time it takes for the service provider to provide the required data. If you have an estimate of the time required, e.g. a month, then you can use the personnel on other projects until the data has arrived and then continue with the project. Although the report is the final product produced, the expert needs to appear as an expert witness in court, which needs to be factored in when planning the supply chain. However, it is difficult to place a time frame to it, hence the exclusion in this example. The author was involved in cases that the court proceedings happened two to five years later after the forensic mapping was completed owing to various judicial processes initiated by both the prosecution and the defence. The supply chain provides a framework to refresh the expert's mind on the processes followed since these may crop up during cross-examination by both the defence and the prosecution.

Bolstorff and Rosenbaum (2007) indicate that a single commodity such as this example can be mapped and on the other hand the company's supply chain for product ranges can be mapped to improve the overall production of products to be competitive in the market place. With regards to mapping a supply chain to improve the general competitiveness of a GIS unit it is suggested to use the Pareto principle, namely identify those few projects that brings in highest amount of income to a GIS firm or unit, and understand these to improve the overall supply chain of the GIS unit. The first round of mapping is known as the "AS IS" and once the AS IS has been measured, the TO BE supply chain can be developed (Bolstorff \& Rosenbaum, 2007 and Schmitz, 2007). The mapping of the supply chain using the SCOR model can be done using standard office software and is not dependent on sophisticated software programs.

Using supply chains and supply chain management in the context of GIS is still in its infancy although some research is being conducted as indicated in Section 2. Future research should include case studies to understand the supply chains of GIS units or firms in order to improve their production and competitiveness. From these case studies develop a model using the SCOR model as a framework that takes into account the specifics of the GIS industry that is different from a normal extraction, manufacturing, distribution and sales processes for which the SCOR model has been developed. 


\section{Acknowledgements}

The author would like to acknowledge the CSIR for the opportunity to write this paper, the Directorate of Priority Crime Investigations (Hawks) to use this fraud case as an example and the peer reviewers for their valuable input. The independent reviewers are acknowledged for their valuable inputs and suggestions to improve this paper.

\section{References}

Altmaier, A \& Kolbe, TH, 2003, 'Applications and Solutions for Interoperable 3D Geo-Visualization' in Fritsch, D (ed.) Proceedings of the Photogrammetric Week 2003 in Stuttgart, Wichmann Verlag.

Bolstorff, P \& Rosenbaum, R, 2007, Supply Chain Excellence: A Handbbok for Dramatic Improvement Using the SCOR Model, $2^{\text {nd }}$ Edition, AMACOM, New York, USA.

Christopher, M, 1998, Logistics and Supply Chain Management: Strategies for Reducing Cost and Improving Service, $2^{\text {nd }}$ Edition, Financial Times, Prentice Hall, Pearson Education Limited, Harlow, Essex, UK.

Handfield, RB \& Nichols, EL, 1999, Introduction to Supply Chain Management. Prentice Hall, Upper Saddle River, USA.

Kraak, M-J, 2003, 'Geovisualization illustrated' in ISPRS Journal of Photogrammetry \& Remote Sensing vol. 57 pp. 390-399

Kristensson, PO, Dahlbäck, N, Anundi, D, Björnstad, M, Gillberg, H, Haraldsson, J, Mårtensson, I, Nordvall, M, \& Ståhl J, 2008, The Trade-offs with Space Time Cube Representation of Spatiotemporal Patterns. arXiv:0707.1618v1 [cs.HC] 11 Jul 2007

Lochner, H \& Zinn, R, 2014, 'Detecting invisible traces generated by a cellphone at a crime scene' in Acta Criminologica: Southern African Journal of Criminology, vol. 27, no. 1, pp. 160-175

Kurwakumire, E, Coetzee, S \& Schmitz, P, 2013, 'Towards Modelling the SDI Supply Chain in South Africa: The Case of Land Administration Data', in H Onsrud (ed), GSDI 2014 Proceedings, GSDI, Addis Ababa, Ethiopia, 4 - 8 November 2013. Paper delivered by Edward Kurwakumire. Available from http://www.gsdi.org/gsdiconf/gsdi14/papers/191-Chapter2.pdf

Kurwakumire, E, Coetzee, S, Schmitz, P \& Mdubeki, S, 2014, 'Supply Chain Mapping for Visualising the SDI in South Africa: A Case of Land Administration Data.' In J. Whittal and S. Motala, 2014: Welcome to AfricaGEO 2014: Proceedings of the Second AfricaGEO Conference, CONSAS Conference, 2014, ISBN 978-0-620-60666-0

Mentzer, JT, DeWitt, W, Keebler, JS, Min, S, Nix, NW, Smith, CD \& Zacharia, ZG, 2001, 'What is supply chain management?' in Mentzer, JT (ed.) Supply Chain Management, Sage Publications, Thousand Oaks, USA.

SCC (Supply-Chain Council) 2008, SCOR: Supply-Chain Operations Reference Model, Version 9.0. Supply-Chain Council, Pittsburgh, USA.

Schmitz, PMU, 2007, 'The use of supply chains and supply chain management to improve the efficiency and effectiveness of GIS units'. Unpublished PhD thesis, University of Johannesburg, Johannesburg, South Africa.

Schmitz, P, 2008, 'Using supply chain management to enable GIS units to improve their response to their customers' needs.' In Academic Proceedings of the 2008 Free and Open Source Software for Geospatial conference, ISBN 978-0-620-42117-1. 
Schmitz, PMU, 2009, 'Using supply chain management to enable GIS units to improve their response to their customer's needs' in South African Computer Journal, vol. 43, pp. 58-65

Schmitz, P, 2011, 'Using Supply Chain Management as a Tool to Manage GIS Projects'. V1 Magazine: Promoting Spatial Design for a Sustainable Tomorrow. Monday, 14 November 2011. URL http://www.vector1media.com/article/features/24167-using-supply-chain-management-as-atool-to-manage-gis-projects-.html

Schmitz, PMU, Cooper, AK, Davidson, A \& Rossouw, K, 2000, 'Breaking Alibis Through Cell Phone Mapping' in LaVigne, N \& Wartell, J (eds.) Crime Mapping Case Studies - Successes in the Field Volume 2, Police Executive Research Forum, Washington, USA.

Schmitz, P, Cooper, A, Kruger, T, Speed, K, Barkhuizen, M, Lochner, T \& Linnen, C, 2015, 'Space Time Visualisation for Investigative and Forensic Purposes' in Robbi Sluter, C, Madureira Cruz, CB \& Leal de Menezes, PM (eds.) Cartography - Maps Connecting the World. 27th International Cartographic Conference 2015. Publications of the International Cartographic Association (ICA). Springer International Publishing, Switzerland. ISBN 978-3-319-17737-3

Schmitz, P, de la Rey, A \& Marais, M, 2005a, 'The use of Supply Chain Management to plan and manage large or data intensive GIS projects.' In Beyond Talk - Geo-Information working for Africa. Conference proceedings of the AfricaGIS 2005 conference held in Tshwane, South Africa, 31 October to 4 November 2005. ISBN 1-920-01710-0

Schmitz, P, de la Rey, A \& Marais, M, 2005b, 'Using Supply Chain Management and SCOR in Managing Geographic Information System Products.' In Supply Chains in Rhythm. SAPICS Annual Conference, Sun City, South Africa, 5 to 8 June 2005. ISBN 1-920-01713-5

Schmitz, P, Eloff, C, Talmakkies, R, Linnen, C \& Lourens, R, 2013, 'Forensic Mapping in South Africa: Four Examples' in Cartography and Geographic Information Science, vol. 40, no. 3, pp. $238-247$

Schmitz, PMU, Kampfer, A \& Nelson, M, 2011, 'Using the Supply-Chain Operations Reference Model (SCOR) to model the production of nautical charts by the SA Navy Hydrographic Office' in ICC2011_DIGITAL_PROCEEDINGSIOral Presentations PDF of the 25th International Cartographic Conference in Paris, France, 3 to 8 July 2011. <http://icaci.org/files/documents/ICC_proceedings/ICC2011/Oral\%20Presentations\%20PDF/E3Production\%20and\%20management\%20of\%20thematic\%20data\%20base/CO-458.pdf >

Schmitz, PMU, Riley, S \& Dryden, J, 2009, 'The use of mapping time and space as a forensic tool in a murder case in South Africa' in 24th International Cartographic Conference, Conference Proceedings. The World's Geo-Spatial Solutions. 15 to 21 November 2009, Santiago, Chile. ISBN 978-1-907075-02-5

Schmitz, P, Scheepers, L, de Wit P, \& de la Rey, A, 2007, 'Understanding data supply chains by using the Supply-Chain Operations Reference (SCOR) model.' In Global Supply Chains: Developing Skills, Capabilities and Networks. Conference proceedings of Logistics Research Network Annual Conference 2007. University of Hull, Hull, UK; 5 to 7 September 2007. ISBN 978-1-904564-19-5

Silen, C, Wirell, S, Kvist, J, Nylander, E \& Smedby, O, 2008, 'Advanced 3D visualization in studentcentred medical education.' Medical Teacher, vol. 30, no. 5, pp. 115-124

$\mathrm{Wu}, \mathrm{Q} \& \mathrm{Xu}, \mathrm{H}, 2003$, 'An approach to computer modelling and visualization of geological faults in 3D' in Computers and Geosciences, vol. 29, pp. 503 - 509

\footnotetext{
${ }^{1}$ Bank's identity withheld for privacy, investigative and security reasons.
} 